\title{
Clarke ve Park Dönüşümlerinin Görselleştirilmesi
}

\author{
*Fahri Vatansever \\ *Mühendislik Fakültesi, Elektrik-Elektronik Müh. bölümü, Bursa Uludağ Üniversitesi, Türkiye
}

\section{Özet}

Üç fazlı sistemlerin analizinde en sık kullanılan dönüşümlerin başında Clarke ve Park dönüşümleri gelmektedir. $\mathrm{Bu}$ matematiksel dönüşümler, üç fazlı devrelerin analizlerini kolaylaştırmak için kullanılmaktadırlar. Gerçekleştirilen çalışmada; $\mathrm{ABC}-\alpha \beta 0$-dq0 referans sistemleri arasında etkileşimli olarak çift yönlü dönüşümleri yapabilen bir yazılım geliştirilmiş̧ir. Konu anlatımları da içeren yazılım ile Clarke ve Park dönüşümlerinin görselleştirilerek iyice kavranılması amaçlanmıştır.

Anahtar kelimeler: Clarke dönüşümü, Park dönüşümü, mühendislik eğitimi.

\section{The Visualization of Clarke and Park Transforms}

\begin{abstract}
Clarke and Park transformations are the most commonly used transformations in the analysis of threephase systems. These mathematical transformations employed to simplify the analysis of three-phase circuits. In this study; a software has been developed that can perform bidirectional conversions between $\mathrm{ABC}-\alpha \beta 0$-dq0 reference systems, interactively. With the developed software also including topic descriptions, Clarke and Park transformations is aimed to be comprehended by visualizing.
\end{abstract}

Key words: Clarke transform, Park transform engineering education.

\section{Giriş}

Üç fazlı makinelerin davranışları, genellikle zamanla katsayıları değişen (sabit rotorlu hariç) gerilim ve akım diferansiyel denklemleriyle ifade edilmektedirler. Dolayısıyla bu tür sistemlerin modellenmesi karmaşık olup analizi de zordur. Ancak matematiksel ifadelerdeki değişkenleri; ortak bir referans sistemine (çerçevesine) yönlendirmek, çözümleri kolaylaştırmaktadır. Bu nedenle üç fazlı makinelerin/sistemlerin/devrelerin çözümünde sıklıkla matematiksel dönüşümler kullanılmaktadır. Bu dönüşümler arasında en bilinenleri Clarke ve Park dönüşümleridir.

Teknolojideki hızlı gelişmeler; hem teorik hem de pratik alanda bilgisayarlardan yüksek oranlarda faydalanılmasını kaçınılmaz hale getirmiştir. Uygulama (pratik) alanlarında bilgisayar destekli mühendislik, bilgisayar destekli tasarım, bilgisayar destekli üretim gibi kavramlar sık sık kullanılırken eğitim (teorik) alanında da bilgisayar destekli eğitim, bilgisayar destekli öğretim, uzaktan eğitim, sanal laboratuar, arttırılmış gerçeklik gibi birçok kavramlardan

*Corresponding author: Address: Faculty of Engineering, Department of Electrical-Electronics Engineering, Bursa Uludağ University, 16059, Bursa TURKEY. E-mail address: fahriv@ @uludag.edu.tr, Phone: +90 2242940905 
faydalanılmaktadır. Günümüzde uygulama alanlarına özel yazılımlar[1-3], eğitim programları, multimedya gereçler, simülatörler, sanal laboratuarlar, uzaktan erişimler, web sayfaları vb. geliştirilmişlerdir[4-9].

Gerçekleştirilen çalışmada; özellikle elektrik mühendisliğindeki üç fazlı sistemlerin/devrelerin analizinde kullanılan dönüşümlere yönelik eğitim amaçlı bir simülatör tasarlanmıştır. Konu anlatımları içeren ve kullanıcı dostu arayüze sahip simülatör ile kullanıcılar/öğrenciler etkileşimli görsel uygulamalar gerçekleştirerek ilgili dönüşümleri kolay, hızlı ve etkin bir şekilde öğrenip kavrayabilmektedirler.

\section{Clarke ve Park Dönüşümleri}

\subsection{Clarke dönüşümü}

Clarke veya diğer adıyla $\alpha \beta 0$ dönüşümü, elektrik mühendisliğindeki üç fazlı devrelerin analizini basitleştirmek için kullanılan matematiksel bir dönüşümdür. Bu uzay vektör dönüşümüyle doğal üç fazlı koordinat sistemindeki zaman domeni işaretleri, sabit iki fazlı referans sisteme $(\alpha \beta)$ dönüştürülmektedir (Tablo 1)[10-13].

Tablo 1. Clarke $(\alpha \beta 0)$ dönüşümleri

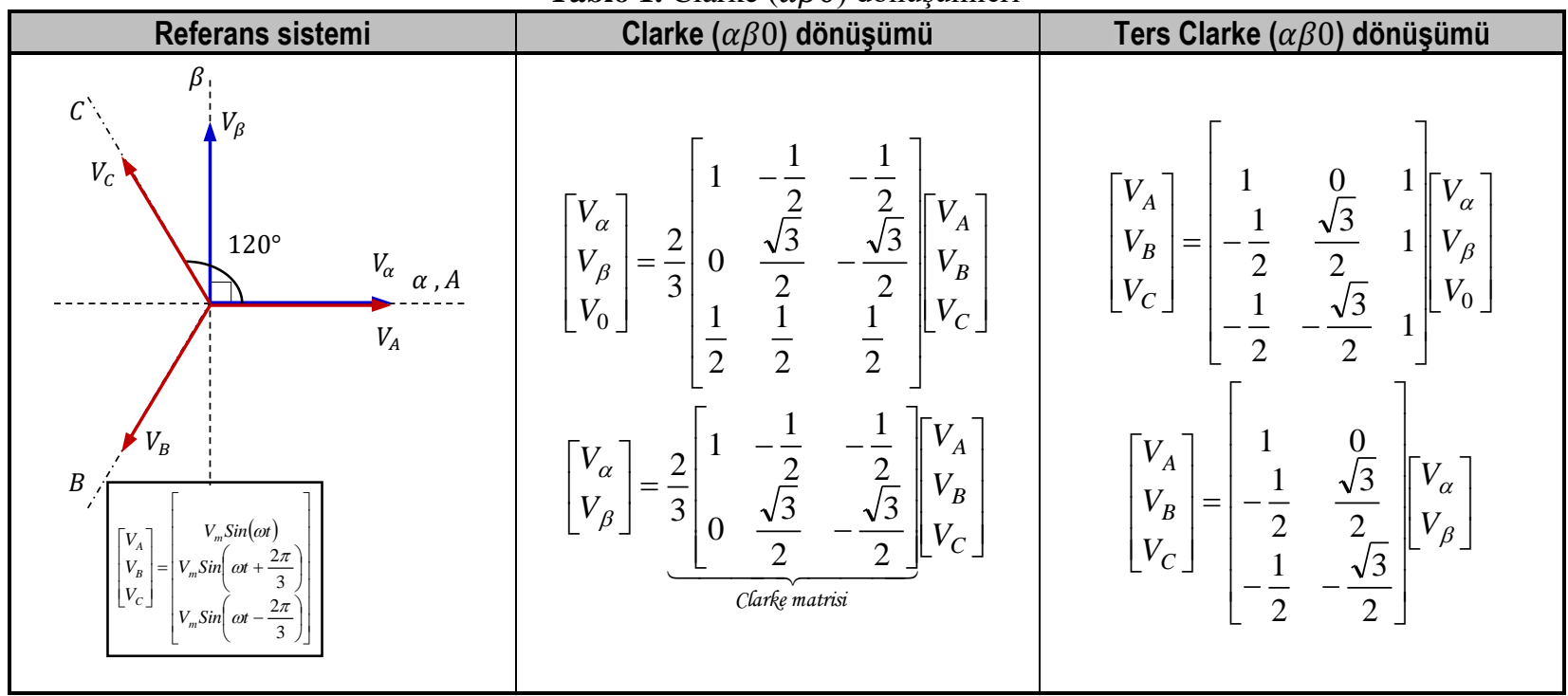

\subsection{Park dönüşümü̈}

Park dönüşümü veya diğer adıyla dq0 (direct-quadrature-zero) dönüşümü, elektrik mühendisliğindeki üç fazlı devrelerin analizini basitleştirmek için kullanılan diğer bir matematiksel dönüşümdür. $\mathrm{Bu}$ dönüşümle $\alpha \beta$ referans sistemindeki işaretler, dönel koordinat sistemine (dq) dönüştürülmektedir (Tablo 2). Tablo 3 'te ise referans sistemleri arasındaki geçişlerde kullanılan ifadeler özetlenmektedir)[10-14]. 
Tablo 2. Park $(d q 0)$ dönüşümleri

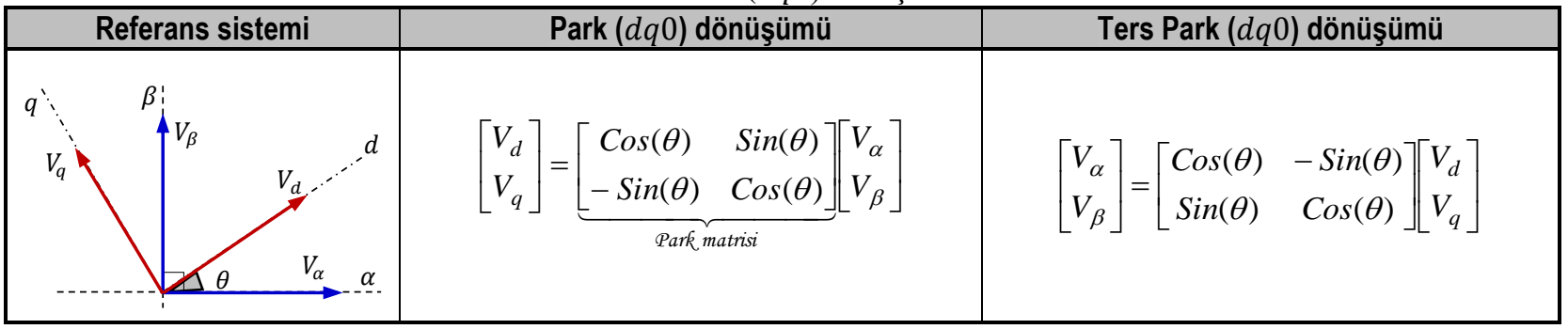

Tablo 3. $A B C-\alpha \beta-d q$ referansları arasındaki geçişler

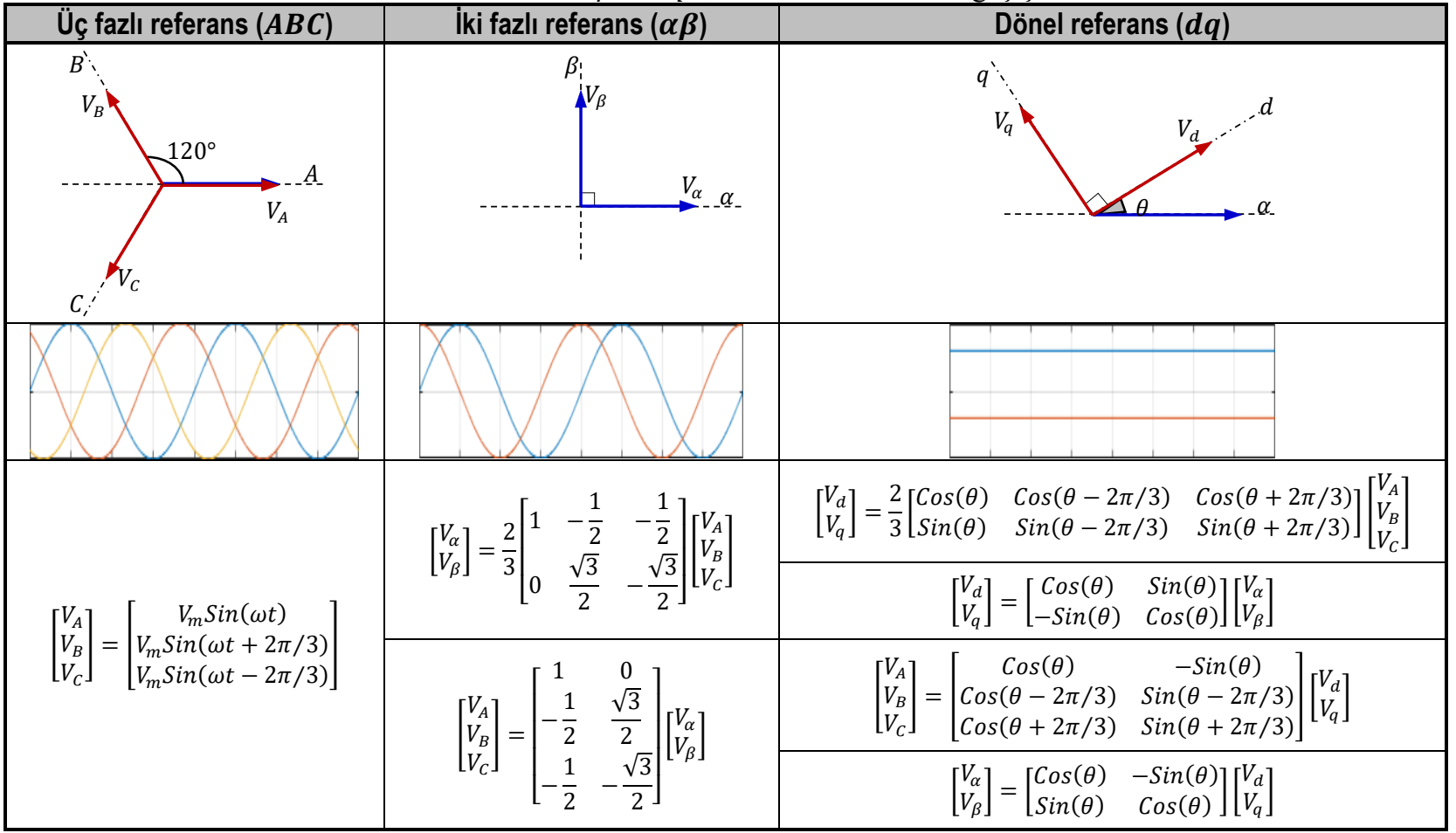

\section{Geliştirilen Yazılım ve Uygulamaları}

Visual C\#[15] kullanılarak geliştirilen programın ana ekranı Şekil 1 ve örnek uygulaması Şekil 2'de verilmektedir. Programda $A B C-\alpha \beta-d q$ referans sistemlerindeki işaretler görüntülenmekte, ilgili sistemler arasındaki çift yönlü dönüşümler etkileşimli olarak yapılabilmekte, sayısal ve grafiksel sonuçlar elde edilebilmekte, kaydedilebilmekte, yazdırılabilmekte ve konu anlatımları incelenebilmektedir. Herhangi bir referans sistemindeki işaretlerden/bileşenlerden herhangi birisinin parametresi kullanıcı tarafından değiştirildiğinde eşzamanlı olarak - diğer referans sistemlerindeki işaretler/bileşenler güncellenmektedir. Böylece işaret/bileşen parametrelerinin referans sistemlerindeki etkileri/yansımaları anlık olarak görüntülenebilmektedir. Görselleştirilen bu değişimler de ilgili referans sistemlerinin kullanıcılar/öğrenciler tarafından daha kolay kavranmasını sağlamaktadır. 


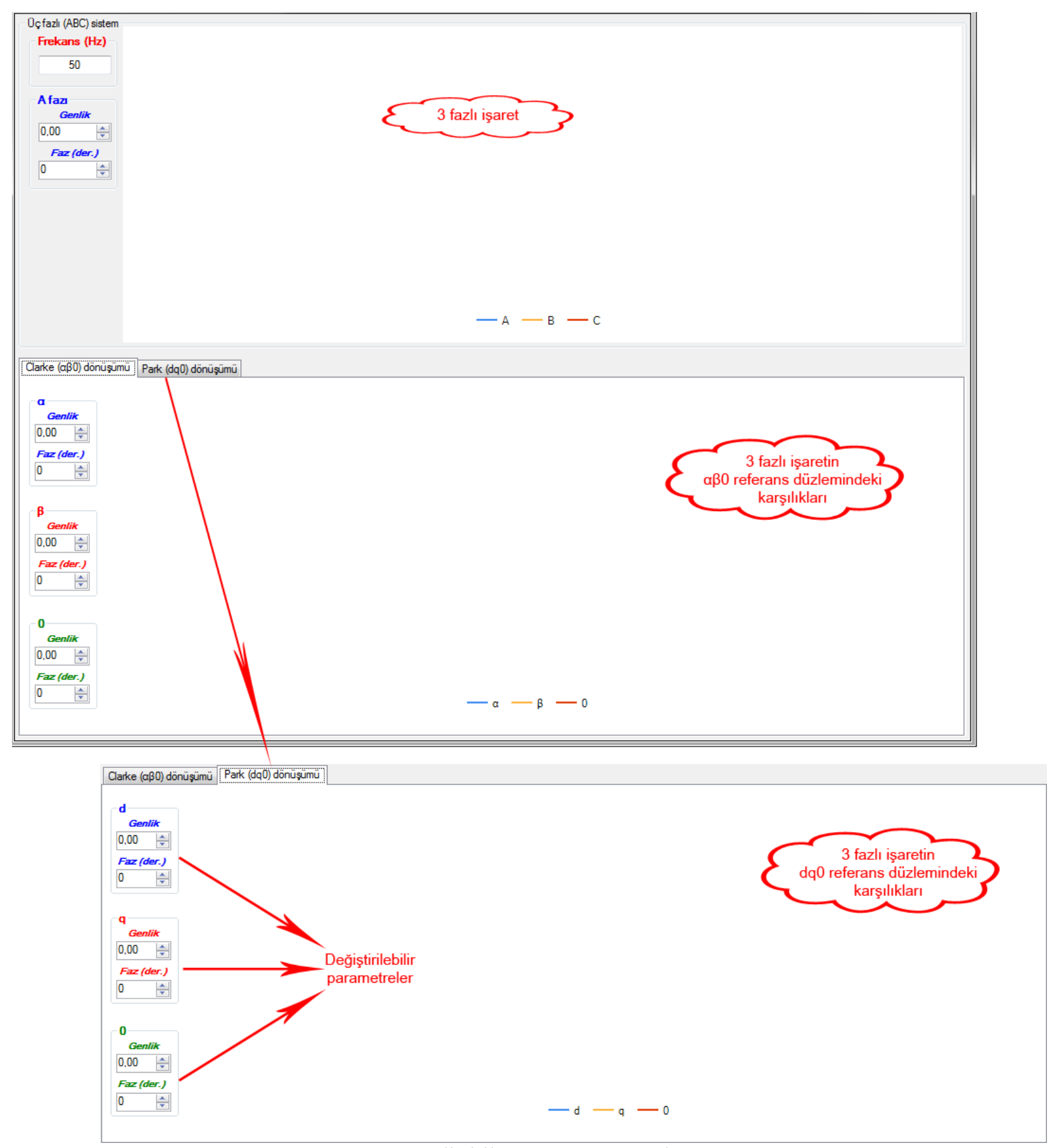

Şekil 1. Geliştirilen programın ana ekranı 


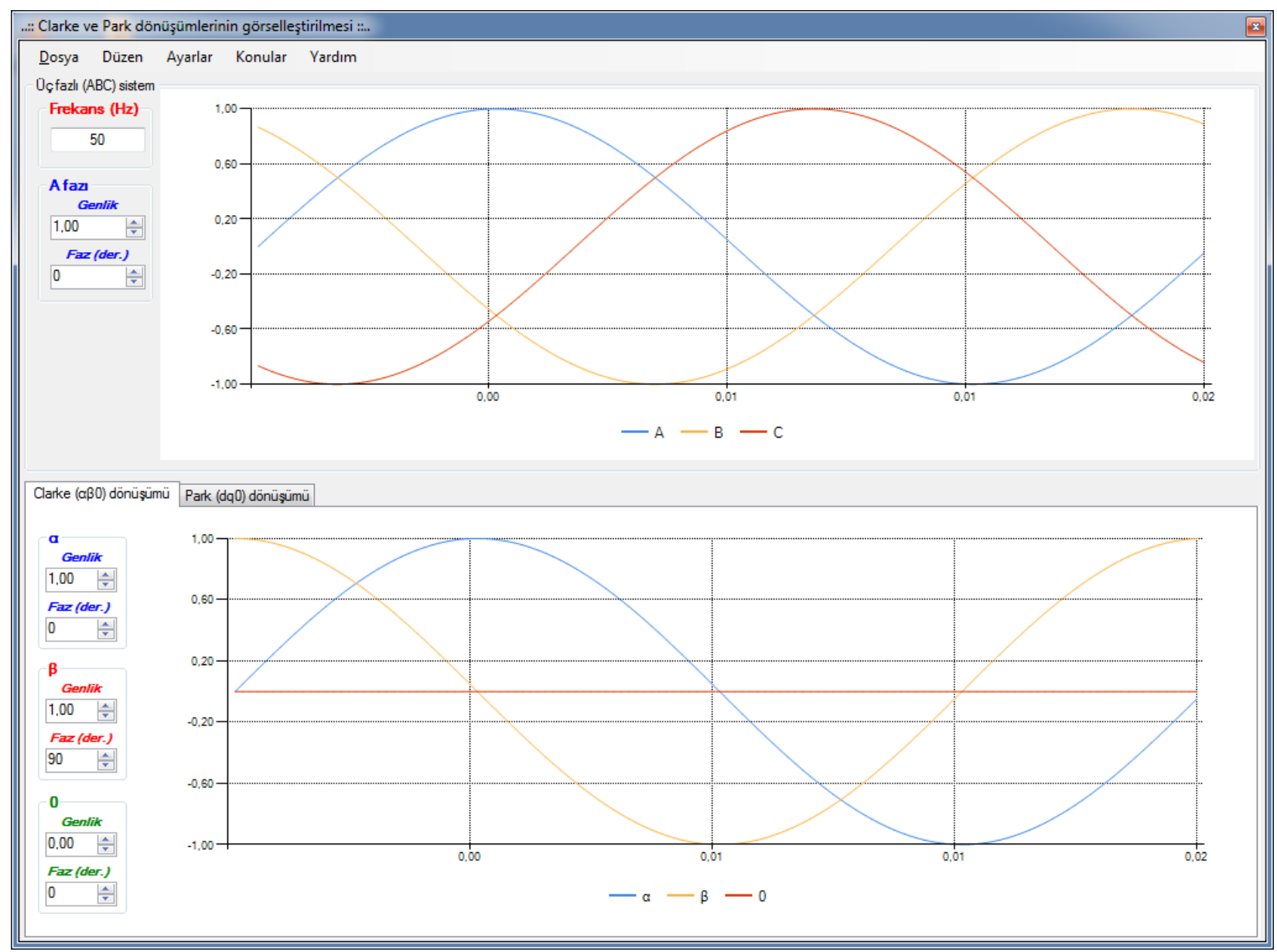

Şekil 2. Geliştirilen programın örnek ekran görüntüsü

\section{Sonuçlar}

Gerçekleştirilen çalışmada; elektrik mühendisliğinde üç fazlı sistemlerin/devrelerin incelenmesini (analizini) - farklı referans sisteminde/çerçevesinde iki bileşene düşürerek - kolaylaştıran Clarke ve Park dönüşümlerinin daha kolay ve etkin şekilde yapılması ve kavranması için bir yazılım geliştirilmiştir. Konu anlatımları da içeren yazılım ile üç referans sistemi arasındaki çift yönlü dönüşümler etkileşimli olarak kolay, hızlı ve etkin bir şekilde yapılabilmekte; sayısal ve grafiksel olarak görüntülenebilmekte; parametre değişimlerinin etkileri anlık olarak gözlenebilmektedir.

\section{Kaynaklar}

[1] MATLAB, The MathWorks, Inc. 2013.

[2] LabVIEW, The National Instruments.

[3] OrCAD PSpice, Cadence Design Systems.

[4] Balamuralithara B, Woods PC. Virtual laboratories in engineering education: The simulation lab and remote lab. Comput. Appl. Eng. Educ. 2009; 17: 108-118.

[5] Yalcin NA, Vatansever F. A web-based virtual power electronics laboratory. Comput. Appl. Eng. Educ. 2016; 24: 71-78. 
[6] Vatansever F, Yalcin NA. E-Signals\&Systems: A web-based educational tool for signals and systems. Comput. Appl. Eng. Educ. 2017; 25: 625-641.

[7] Vatansever F, Hatun M. Sistem analizi eğitim simülatörü tasarımı. In: Proceedings of ISITES'2014; 546-550.

[8] Vatansever F, Yalcin NA, Kuyu YC. Gürültü temizleme simülatörü tasarımı. In: Proceedings of ISITES'2015; 973-980.

[9] Vatansever F, Hatun M. The system stability software tool based on Routh-Hurwitz criterion. Uludağ University Journal of The Faculty of Engineering.2019; 24(2): 229-238.

[10] Clarke E. Circuit analysis of A-C power systems. Vol. I. USA: John Wiley \& Sons; 1950.

[11] Krause P, Wasynczuk O, Sudhoff S, Pekarek S. Analysis electric machinery and drive systems. $3^{\text {rd }}$ ed. USA: IEEE Pres \& Wiley; 2013.

[12] Chattopadhyay S, Mitra M, Sengupta S. Electric Power Quality. Springer; 2011.

[13] Microsemi Co. Park, inverse Park and Clarke, inverse Clarke transformations mss software implementations user guide. 2013.

[14] Park RH. Two reaction theory of synchronous machines: Generalized method of analysisPart I. In: The Winter Convention of the A. I. E. E., New York, Jan. 28-Feb. 1, 1929; 716727.

[15] Microsoft Co. Visual Studio. 2013. 